\title{
A Study on Utilization of Maternal Health Services and Factors Influencing the Utilization in Urban Slums of Lucknow
}

\author{
Chopra Deepak', Jauhari ${ }^{2}$, Dhungana $\mathrm{H}^{3}$
}

\begin{abstract}
Introduction: Despite various health programs and policies in the country, maternal health care service utilization by eligible women remains sub-optimal esp. in disadvantaged subsets of population. Aim and Objectives: The present study was conducted with an aim to assess the utilization of maternal health care services (ANC and PNC) and the factors influencing maternal health care utilization in urban slums of Lucknow. Materials and Methods: Study design- Cross Sectional. Study Area- Urban slums of Lucknow. Study Unit-Women who had delivered in the past one year. Study Period-July, 2014 to March, 2015. Sampling Technique Simple random sampling. Sample Size-968 participants. Study Technique- Personal Interviews using a pre-tested, pre-structured questionnaire. Results: The study observed that utilization of maternal health care services was sub-optimal, few indicators being abysmally low like PNC visits (5\%). Socio-demographic factors like education of women, religion and parity was found to be significantly associated with Maternal health care utilization. Discussion: Current study re-emphasized that utilization of maternal health care services is affected by multiple socio-demographic factors like maternal education, religion and parity of women. Education increases awareness about health, availability and accessibility of services and help develop the confidence while religious faith also decides the utilization of services. Conclusion: The better utilization of the maternal health services can be achieved by overall socio-economic development including focus on women empowerment and education, focus on religious norms and faiths in the health policies. Recommendations: Policies and programs focusing on education of community especially women and girls and incorporation of opinions of religious bodies could be an appropriate strategy.

Key words: Maternal Healthcare, Ante-natal Care, Post-natal Care, Utilization.
\end{abstract}

\section{Chopra Deepak', Jauhari N², Dhungana $\mathrm{H}^{3}$}

'Department of Community Medicine, IIMSR, Lucknow, Uttar Pradesh, INDIA. ${ }^{2} D N B$ Consultant, Fatima Hospital, Lucknow, Uttar Pradesh, INDIA. ${ }^{3}$ Department of Community Medicine, IIMSR, Lucknow, Uttar Pradesh, INDIA.

\section{Correspondence}

Dr Deepak Chopra

L-4/169A, Vinay Khand-4

Gomti Nagar,-226010. Lucknow,

Uttar Pradesh, INDIA

Mobile no: 9451383179

Email: drdeepakchoprakgmu17@gmail.com

\section{History}

- Submission Date: 25-07-2017

- Revised Date: 10-11-2017

- Accepted Date: 24-04-2018

DOI : 10.5530/ijmedph.2018.2.17

Article Available online

http://www.ijmedph.org/v8/i2

\section{Copyright}

(C) 2018 Phcog.Net. This is an openaccess article distributed under the terms of the Creative Commons Attribution 4.0 International license.

\section{INTRODUCTION}

Maternal and child healthcare services are very important for the health outcomes of the mother and that of the child by ensuring that both maternal and child deaths are prevented. ${ }^{1}$ Many health programs have been launched in the country in last two-three decades for women and child health care. Health care utilization overall, and for maternal health specifically, has improved in India mainly due to $\mathrm{NRHM}^{2}$ but Maternal mortality and morbidity continue to be high despite the existence of national programs which could be due to sub optimal levels of utilization of services ${ }^{3-4}$ especially amongst the rural poor and urban slum population. ${ }^{5}$ Studies have also found the need for such services is greatest, i.e., among disadvantaged populations. ${ }^{6-9}$ Various studies conducted worldwide and in India have recognized socio-economic, demographic factors and service delivery environment as important determinants for the use of maternal health services. ${ }^{10-16}$

Uttar Pradesh is one of the eight states which is home to $43 \%$ of India's urban poor with rates of utilization of maternal health services far below the national average. Hence there is a distinctive need of under- standing the factors affecting the use of maternal health services. However, scarce research is available in the context of Uttar Pradesh of India.

Hence the present study was conducted with an aim to assess the utilization of maternal health care services (ANC and PNC) and the association of factors on maternal health care utilization in urban slums in Lucknow. This study is expected to provide the policy makers findings which may help in improving the policy efforts in the ongoing program.

\section{MATERIALS AND METHODS}

This is a cross sectional study conducted in slums of Lucknow district and the study participants were the mothers who have delivered in last one year. The study was conducted from July 2014 to March 2015. The slums were selected randomly and the study unit who has delivered in the last one year was included in the study. Help of local stake holders, door to door survey etc. were taken to identify the study participants. Every eligible participant who consented was enrolled in the study. The sample size calculated was 968 . Sample size was calculated taking

Cite this article : Deepak C, Jauhari N, Dhungana H. A Study on Utilization of Maternal Health Services and Factors Influencing the Utilization in Urban Slums of Lucknow. Int J Med Public Health. 2018;8(2):77-81. 
utilization of Government health services which is around $20 \%{ }^{40}$ Design effect of 1.5 was applied to calculate sample size.

The study was piloted on 100 participants to test the questionnaire and the methodology and necessary corrections were made. The interview was recorded on a pre-tested, pre-structured questionnaire. The Data Analysis was done using SPSS-20.0 version. The tests used for analysis of data were Pearsons Chi - Square Test and $p<0.05$ is taken as significant. Institutional and ethical approval was taken.

\section{RESULTS}

The study observed that the majority of participants were illiterate (71.4\%) and housewives (78.8\%). It was further observed that $96.4 \%$ of

\section{Table 1: Biosocial Characteristics of Study Participants.}

\section{Biosocial characteristics $(\mathrm{N}-968)$}

\begin{tabular}{|c|c|c|}
\hline Age of Participant (women) & No. & Percent \\
\hline $15-24$ yrs & 414 & 42.8 \\
\hline $25-34$ yrs & 493 & 50.9 \\
\hline 35 and above & 61 & 6.3 \\
\hline \multicolumn{3}{|l|}{ Religion of Participant } \\
\hline Hindu & 451 & 46.6 \\
\hline Muslim & 517 & 53.4 \\
\hline \multicolumn{3}{|l|}{ Literacy Level of Participant } \\
\hline Illiterate & 691 & 71.4 \\
\hline Upto primary & 156 & 16.1 \\
\hline Upto intermediate & 101 & 10.4 \\
\hline Graduate or higher & 20 & 2.1 \\
\hline \multicolumn{3}{|l|}{ Occupation of Participant } \\
\hline Unskilled & 185 & 19.1 \\
\hline Business & 20 & 2.1 \\
\hline House Wife & 763 & 78.8 \\
\hline \multicolumn{3}{|l|}{ Education of Husband } \\
\hline Illiterate & 474 & 49.0 \\
\hline Upto primary & 459 & 47.4 \\
\hline Upto intermediate & 32 & 3.3 \\
\hline Graduate or higher & 3 & 0.3 \\
\hline \multicolumn{3}{|l|}{ Occupation of Husband } \\
\hline Skilled & 241 & 24.9 \\
\hline Unskilled & 447 & 46.2 \\
\hline Business & 176 & 18.2 \\
\hline Pvt Job & 80 & 8.3 \\
\hline Unemployed & 24 & 2.5 \\
\hline \multicolumn{3}{|l|}{ Parity of Participant } \\
\hline Less than equal to 2 & 474 & 49.0 \\
\hline 3 to 5 & 414 & 42.8 \\
\hline More than 5 & 80 & 8.3 \\
\hline \multicolumn{3}{|l|}{ Type of Family } \\
\hline Nuclear & 436 & 45.0 \\
\hline Joint family & 532 & 55.0 \\
\hline
\end{tabular}

husband of study participants were either illiterate or literate upto primary level (Table 1). Table 2 depicts that $77 \%$ of study participants were registered for ANC (Figure 1), majority of whom being registered at a govt. maternity center $(78.6 \%)$. ANC registered participants who undertook more than three ANC visits were low (15.3\%) and only one third of these participants undertook first ANC visit during the first trimester. Approximately two-third of registered participants did not receive IFA tablets and $96.6 \%$ of participants had either one or two doses of TT vaccination. About $95 \%$ of all study participants didn't undertake PNC visit.

Table 3 shows that on statistical analysis the religion was associated with the ANC and PNC visit and the association was statistically significant $\left(X^{2}-26.0\right.$, d.f. $=1, p=0.000 ; X^{2}-3.87$, d.f. $\left.=1, p=0.049\right)$. Literacy level of participants was also found to statistically significant with ANC

\begin{tabular}{|c|c|c|}
\hline Registered during $\mathrm{ANC}(\mathrm{N}=968)$ & No. & Percent \\
\hline Yes & 744 & 76.9 \\
\hline No & 224 & 23.1 \\
\hline
\end{tabular}

Any PNC visit undertaken

Yes

54

5.6

No

914

94.4

ANC services availed among those registered $(\mathrm{N}=744)$

No.

Percent

Place of Registration

Govt. Maternity Centre

Private Hospital

17.6

Other

No. of ANC Visits undertaken

$\begin{array}{ccc}\text { One } & 43 & 5.8 \\ \text { Two } & 316 & 42.5 \\ \text { Three } & 271 & 36.4 \\ \text { More than Three } & 114 & 15.3\end{array}$

First ANC Checkup undertaken during

$\begin{array}{ccc}\text { First Trimester } & 263 & 35.3 \\ \text { Second Trimester } & 359 & 48.3 \\ \text { Last Trimester } & 122 & 16.4\end{array}$

\section{IFA Tablets}

Received

Less than 100

More than 100

not received

480

64.5

Consumed $(\mathrm{n}=264)$

Less than 100

More than 100

not consumed

T.T. Vaccine

$\begin{array}{lcc}\text { One Dose } & 123 & 16.5 \\ \text { Two Dose } & 596 & 80.1 \\ \text { No Dose } & 25 & 3.4\end{array}$




\begin{tabular}{|c|c|c|c|c|c|c|}
\hline & \multicolumn{2}{|c|}{ ANC visit } & & \multicolumn{2}{|c|}{ PNC visit } & \\
\hline & Yes & No & & Yes & No & \\
\hline Religion(N-968) & & & \multirow{3}{*}{$\begin{array}{c}\mathrm{X}^{2}-26.0, \text { d.f. }=1 \\
\mathrm{p}=0.000\end{array}$} & & & \multirow{3}{*}{$\begin{array}{c}\mathrm{X}^{2}-3.87 \\
\text { d.f. }=1 \\
\mathrm{p}=0.049\end{array}$} \\
\hline Hindu & 380 & 71 & & 32 & 416 & \\
\hline Muslim & 364 & 153 & & 22 & 498 & \\
\hline \multicolumn{7}{|c|}{ Literacy level of Participant (N-968) } \\
\hline Illiterate & 483 & 208 & \multirow{4}{*}{$\begin{array}{c}\mathrm{X}^{2}-66.5 \text {, d.f. }=3 \\
\mathrm{p}=0.000\end{array}$} & 27 & 664 & \multirow{4}{*}{$\begin{array}{c}\mathrm{X}^{2}-24.6 \\
\text { d.f. }=3 \\
\mathrm{p}=0.000\end{array}$} \\
\hline Up to primary & 148 & 8 & & 9 & 147 & \\
\hline Up to intermediate & 93 & 8 & & 16 & 85 & \\
\hline Graduate or higher & 20 & 0 & & 2 & 18 & \\
\hline \multicolumn{7}{|c|}{ Husband's education status (N-968) } \\
\hline Illiterate & 363 & 111 & \multirow{5}{*}{$\begin{array}{c}\mathrm{X}^{2}-0.243, \text { d.f. }=3 \\
\mathrm{p}=0.97\end{array}$} & 28 & 446 & \multirow{4}{*}{$\mathrm{X}^{2}-2.17$, d.f. $=3, p=0.538$} \\
\hline Upto Primary & 354 & 105 & & 26 & 433 & \\
\hline Upto Intermediate & 25 & 7 & & 0 & 32 & \\
\hline Graduate or Higher & 2 & 1 & & 0 & 3 & \\
\hline \multicolumn{6}{|l|}{ Parity(N-968) } & \\
\hline less than equal to 2 & 384 & 90 & \multirow{3}{*}{$\begin{array}{c}\mathrm{X}^{2}-7.23, \text { d.f. }=2 \\
\mathrm{p}=0.027\end{array}$} & 27 & 447 & \multirow{3}{*}{$\mathrm{X}^{2}-0.63$, d.f. $=2, p=0.969$} \\
\hline three to five & 306 & 108 & & 23 & 391 & \\
\hline more than five & 54 & 26 & & 4 & 76 & \\
\hline \multicolumn{7}{|l|}{ Type of Family(N-968) } \\
\hline Nuclear & 336 & 100 & \multirow{2}{*}{$\begin{array}{c}\mathrm{X}^{2}-0.18, \text { d.f. }=1 \\
\quad \mathrm{p}=0.89\end{array}$} & 24 & 412 & \multirow{2}{*}{$\mathrm{X}^{2}-0.82$, d.f. $=1, \mathrm{p}=0.92$} \\
\hline Joint & 408 & 124 & & 30 & 502 & \\
\hline
\end{tabular}

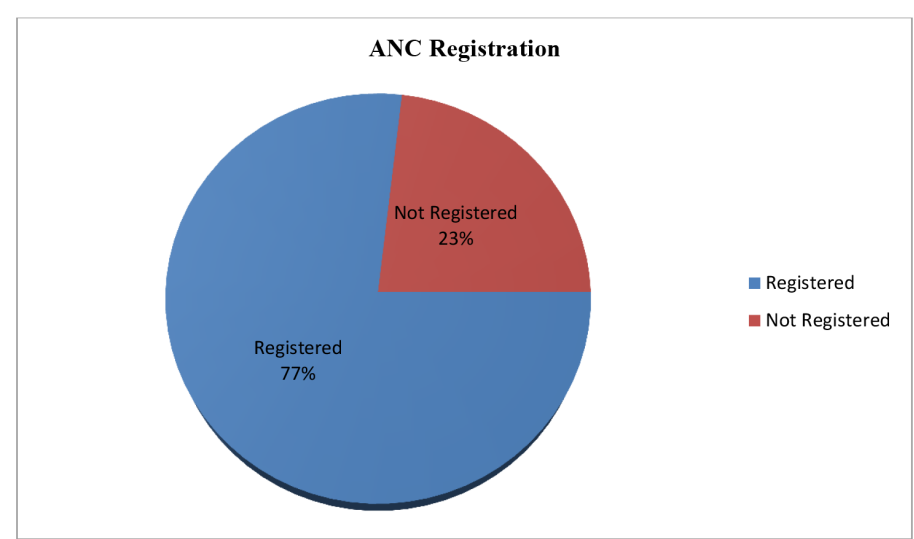

Figure 1: Showing ANC Registration of the Study Participants.

and PNC visits $\left(\mathrm{X}^{2}-66.5\right.$, d.f. $=3$, $\mathrm{p}=0.000 ; \mathrm{X}^{2}-24.6$, d.f. $\left.=3, \mathrm{p}=0.000\right)$. Parity of study participants was found to be statistically significant with ANC service utilization $\left(\mathrm{X}^{2}-7.23\right.$, d.f. $=2$, $\left.\mathrm{p}=0.027\right)$.

\section{DISCUSSION}

Studies have shown that Utilization of health care services is affected by a multitude of factors and many studies have tried to identify the factors that contribute to differentiation in the utilization of health care services ${ }^{17-18}$ Literature available across the world suggests that these factors can be identified as cultural beliefs, socio-demographic status, women's autonomy, economic conditions, physical and financial accessibility and health services issue. ${ }^{19}$

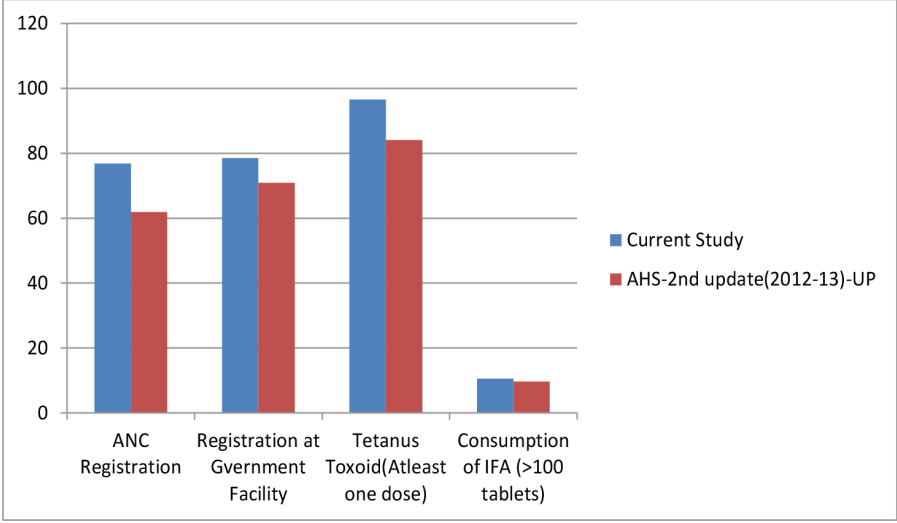

Figure 2: Comparison of Indicators of Current study with Annual Health Survey $\left(2^{\text {nd }} u p d a t e, 2012-13\right)$.

The strength of our study, conducted to find the utilization of maternal health services, was the primary data collected from the study participants. Our study found the literacy level of mother, parity and her religion to be associated with the utilization of maternal health care services (statistically significant $p<0.05$ ). The findings of our study are supported by many studies which have found various socio-demographic factors like maternal education etc. influence the utilization of maternal health services. ${ }^{12-16,20}$

The findings of our study observed that the majority of participants (87\%) were either illiterate or literate upto primary level and the literacy level of mother was found highly statistically significant to be associated with maternal health care utilization. Our findings regarding the influence 
of maternal education on utilization of maternal health care services are consistent with the studies in India and abroad. ${ }^{1-3,20-26}$ A study done in Rohilkhand region by Srivastava, A et al in 2014 also identified a number of demographic and socio-economic factors such as education, religion etc. to be the major causes of poor utilization of primary health care services. ${ }^{17}$ Some studies have also found that women with low level of education are less likely to access antenatal services, even if they are provided. $^{27-29}$

There may be a number of reasons for association of women literacy level with maternal health care utilization like education increases the communication within the family especially with the husband on health related issues and helps the women to develop confidence to take decisions regarding her health. ${ }^{23}$ Educated women seek out better service quality, has a greater ability to improve their health by using health related inputs. Studies have proven the more the women is educated, the more they are aware about their health, know more about availability of maternal health care services and use this awareness and information in accessing and availing the health care services. ${ }^{25,26}$ Our study also observed that literacy level of husband was not associated significantly statistically with maternal health utilization and the findings of our study are in contrast with other studies. ${ }^{5,20,31}$

Our study also found that the association of religion is statistically significant with respect to use of Ante-Natal and Post Natal care by mothers. The similar findings were reported from other studies as well. ${ }^{2-3,21-22}$ Studies from other sub-continent countries like Pakistan ${ }^{32,33}$ and Bangladesh ${ }^{34}$ observed religion to be an important predictor of health outcomes, independent of socio-economic factors. But a study conducted by Jat et al in 2011 found that religion had considerable influence on the use of ANC and safe delivery services whereas no noteworthy influence of these factors was found on post natal care and also observed that women from schedule tribes population and Hindu religion were least likely to be users of the three dimensions of maternal health services. ${ }^{31}$ Similarly, a study conducted by Singh, PK et al in 2012 found that the postnatal care was utilized more by women from other religious groups (42\%), followed by Hindu (35\%) and Muslim (30\%) women. ${ }^{30}$

Studies have attributed differences (lifestyle and theological) between different religions to the greater level of maternal health service utilization among different religions. ${ }^{35}$ Some norms and characteristics of religious groups may encourage negative attitudes healthcare service utilization. ${ }^{36}$ Evidence from African country suggests that collaboration between religious leaders and health officials are vital for changes in health. ${ }^{37}$ Hence considering the influence the religion exerts, its inclusion and involvement of religious bodies in the maternal health services programs may have a positive impact on overall utilization of health services.

The Current study also found that the utilization of maternal health care services (ANC and PNC) decreased as the birth order (parity) of the study participant increases. The finding was supported by other studies and the association of parity with the ANC utilization of maternal health care services was found to be statistically significant. ${ }^{2-3,21,17}$ The reason could be mothers with lesser number of child (esp. with the first child) are more cautious and concerned about pregnancy and thus likely to undertook healthcare visits. ${ }^{38}$ Further, one more explanation could be that as the parity increases, women have an experience and knowledge of earlier pregnancies and related conditions and they may have a belief that healthcare may not be as necessary. ${ }^{24}$ Other reason may be the cultural practice of women going to her maternal place for delivery (esp. the first pregnancy). May be for these reasons, the maternal health care utilization could be decreasing with higher parity.

We also observed that the study participant residing in nuclear families were availing ANC services almost similar to the participants residing in joint families. The association between them was also not statistically significant and the findings were in contrast to the study done by Srivastava et al in 2014 at Rohilkhand. ${ }^{17}$ This requires further research into the matter.

Utilization of maternal health care services like ANC registration, Registration at Govt. facility, Consumption of IFA (more than 100 tablets), at least one dose of tetanus Toxoid is found to be better in our study in comparison to Annual Health Survey ( $2^{\text {nd }}$ update 2012-13) while the First ANC visit in First trimester was lower in comparison to AHS $^{39}$ (Figure 2). The reason may be that our study confined to small area may not represent the state level scenario. Our study observed that $78 \%$ of ANC care was received from Govt. maternity center while the same was also found by Delhi slum study ${ }^{5}$ and a study in Rohilkhand region of UP also found that Majority of the women received ANC from a government functionary. ${ }^{17}$ The low level of PNC in our study was in accordance with other studies ${ }^{1,5}$ The low utilization of Postnatal Care services could be explained by that the mother may believe that it is not necessary to go back for check-ups after delivery without complications.

\section{CONCLUSION}

Even though there is a high utilization rate of antenatal maternal health services in urban slums of Lucknow, still there is scope of improvement. The use of postnatal services is dismal. The low PNC services puts the mother at undue risk of maternal mortality, therefore postnatal care should not be overlooked. The better utilization of the maternal health services can be achieved by overall socio-economic development including focus on women empowerment and education, incorporation of religious norms and faiths in the health policies. Interventions should focus on factors like overall literacy levels of couple, parity and religion. It is also suggested that further research should be carried out to study issues with low use of PNC and the qualitative aspect of maternal health care services. The potential beneficiaries of our study would be the community and the mother in particular. We also suggest that future studies could use the qualitative approach to study issues associated with the low use of postnatal services. Further organizations working on maternal health care services may find the results of this study as an input in their planning for improving utilization of maternal health care services.

\section{Recommendations}

Based on the findings of our study, we recommend that focusing and improving education of community in general and women and girls in particular and incorporation of opinions and norms of religious bodies could be an appropriate strategy to improve the utilization of maternal health care services.

\section{Limitations of the study}

Since the study being the cross sectional, only associations can be examined, causal relationship cannot be. The quantitative assessment of service utilization doesn't comment on the quality of services available and satisfaction/feedback of client. Few other variables which could have potentially influence the pattern of maternal health care utilization were not taken into account like distance of health facility from residence of participants etc.

\section{ACKNOWLEDGEMENT}

We are grateful to the faculty and staff of the department for the support in completion of this study. 


\section{Contribution}

DC conceptualized, designed, data collection, review of literature, draft and finalization of the study, $\mathrm{NJ}$ critical review, finalization of manuscript. $\mathrm{HD}$ analysis of data and preparation of manuscript.

\section{CONFLICT OF INTEREST}

None Declared

\section{ABBREVIATIONS}

ANC: Ante-natal Care; PNC: Post Natal Care; NRHM: National Rural Health Mission; IFA: Iron Folic Acid; TT: Tetanus Toxoid.

\section{SUMMARY}

Various health programs and policies in the country are being implemented in the country but the certain services (like PNC visits) under the maternal health care service utilization by eligible women remains dismally low and these low patterns are affected by various socio-demographic factors. The better utilization of the maternal health services can only be achieved by overall socio-economic development.

\section{REFERENCES}

1. Mluleki Tsawe, AmosMoto, Thendo Netshivhera, Lesego Ralesego, Cassandra Nyathi, ASathiya Susuman. Factors influencing the use of maternal healthcare services and childhood immunization in Swaziland. International Journal for Equity in Health 2015;14(1):32-3

2. Vidler M, Ramadurg U, Charantimath U, Katageri G, Karadiguddi C, Sawchuck, et al. Utilization of maternal health care services and their determinants in Karnataka State, India. Reproductive Health 2016;13(1):37. doi:10.1186/s12978016-0138-8.

3. Kassebaum NJ, Bertozzi-Villa A, Coggeshall MS, Shackelford KA, Steiner C, et al. Global, regional, and national levels and causes of maternal mortality during 1990-2013: A systematic analysis for the Global Burden of Disease Study 2013. Lancet. 2014;384(9947):980-1004. doi:10.1016/S0140-6736(14)60696-6.

4. Omrana P, McClure EM, Wright LL, Saleem S, Goudar SS, Chomba E, et al. A combined community- and facility based approach to improve pregnancy outcomes in low-resource settings: A Global Network cluster randomized trial. BMC Medicine 2013;11(1):215.

5. Agarwal P, Singh MM, Garg S. Maternal health-care utilization among women in an urban slum in Delhi. Indian J Community Med. 2007;32(3):203-5.

6. Bhandari B, Mandowara SL, Kumar A, Agarwal D. Underutilization of $\mathrm{MCH}$ services-the major factor for very high IMR in rural Rajasthan. Indian Pediatr 1989;26(3):228-33.

7. Kloos H. Utilization of selected hospitals, health centres and health stations in central, southern and western Ethiopia. Soc Sci Med. 1990;31(2):101-14.

8. Sarin AR. Underutilization of maternal health services. World Health Forum. 1997;18:67-8.

9. Wilder-Smith A. Current status of 'essential obstetric care' activities internationally: a literature review. Trop Doct. 2003;33(3):135-38.

10. Magadi MA, Madise NJ, Rodrigues RN: Frequency and timing of antenatal care in Kenya: Explaining the variations between women of different communities. Social Science and Medicine. 2000;51(4):551-61.

11. Kesterton AJ, Cleland J, Sloggett A, Ronsmans C. Institutional delivery in rural India: The relative importance of accessibility and economic status. BMC Pregnancy and Childbirth. 2010;10(1):30. doi:10.1186/1471-2393-10-30.

12. Gage A. Barriers to the utilization of maternal healthcare in rural Mali. SocSci Med. 2007;65(8):1666-82

13. Say $L$, Raine R. A systematic review of inequalities in the use of maternal health care in developing countries: Examining the scale of the problem and the importance of context. Bulletin of the World Health Organization. 2007;85(10):812-9. doi:10.2471/BLT.06.035659.

14. Kulkarni M, Nimbalkar M. Influence of socio-demographic factors on the use of antenatal care. Ind J Preventive Soc Med. 2008;39(3):98-102.

15. Babalola S, Fatusi A. Determinants of use of maternal health services in Nigeria - looking beyond individual and household factors. BMC Pregnancy and Childbirth. 2009;9(1):43. doi:10.1186/1471-2393-9-43.
16. Raj Baral Y, Lyons K, Skinner J, Van Teijlingen ER. Maternal health services utilization in Nepal: Progress in the new millennium? Health Sci J. 2012;6(4):618-33

17. Srivastava A, Mahmood S, Mishra P, Shrotriya V. Correlates of Maternal Health Care Utilization in Rohilkhand Region, India. Annals of Medical and Health Sciences Research. 2014;4(3):417-25. doi:10.4103/2141-9248.133471.

18. Sugathan K, Mishra V, Retherford R. Mumbai, India: International Institute for Population Sciences, and Honolulu: East-West Center, Population and Health Studies, USA; 2001. Promoting Institutional Deliveries in Rural India: The Role of Antenatal-Care Services.

19. Shaikh BT, Hatcher J. Health seeking behaviour and health service utilization in Pakistan: Challenging the policy makers. J Public Health (Oxf). 2005;27(1):49-54

20. ZelalemAyele D, Belayihun B, Teji K, Admassu Ayana D. Factors Affecting Utilization of Maternal Health Care Services in Kombolcha District, Eastern Hararghe Zone, Oromia Regional State, Eastern Ethiopia. International Scholarly Research Notices 2014;27:49-54.

21. Goudar SS, Goco N, Somannavar MS, Vernekar SS, Mallapur AA, Moore JL, et al. Institutional deliveries and perinatal and neonatal mortality in Southern and Central India. Reproductive Health. 2015:12(2):13. doi:10.1186/1742-475512-S2-S13.

22. Kumar C, Singh PK, Rai RK. Coverage gap in maternal and child health services in India: assessing trends and regional deprivation during 1992-2006. J Public Health (Oxf). 2013;35(4):598-606.

23. Navaneetham K, Dharmalingam A. Utilization of maternal health care services in southern India. Social Science and Medicine. 2002;55(10):1849-69.

24. Singh L, Rai RK, Singh PK. Assessing The Utilization Of Maternal And Child Health Care Among Married Adolescent Women: Evidence From India. Journal Of Biosocial Science 2012;44(1):1-26. Doi: 10.1017/S0021932011000472.

25. Pallikadavath S, Foss M, Stones RW: Antenatal care in rural Madhya Pradesh: provision and inequality in Obstetric Care in Central India. Southampton: University of Southampton. 2004:111-28.

26. Navneetham K, Dharmalingam A: Utilisation of maternal health care services in Southern India. Social Science and Medicine. 2002;55(10):1849-69.

27. World Health Organization, United Nations Children's Fund. Antenatal care in developing countries-promises, achievements and missed opportunities. Geneva: World Health Organization. 2003.

28. Houweling TA, Ronsmans $C$, Campbell OM, Kunst AE. Huge poor-rich inequalities in maternity care: An international comparative study of maternity and child care in developing countries. Bull World Health Organ. 2007;85(10):745-54.

29. Simkhada B, Teijlingen ER, Porter M, Simkhada P. Factors affecting the utilization of antenatal care in developing countries: Systematic review of the literature. Journal of Advanced Nursing. 2008;61(3):244-60. doi:10.1111/j.1365-2648.2007.04532.

30. Singh PK, Rai RK, Alagarajan M, Singh L. Determinants of Maternity Care Services Utilization among Married Adolescents in Rural India. PLoS ONE. 2012;7(2):316-66. doi:10.1371/journal.pone.0031666.

31. Jat TR, Ng N, San Sebastian M. Factors affecting the use of maternal health services in Madhya Pradesh state of India: A multilevel analysis. International Journal for Equity in Health 2011;10(1):59.

32. Nasir JA, Hinde A. Factors associated with contraceptive approval among religious leaders in Pakistan. Journal of Biosocial Sciences. 2011;43(5):587-96.s

33. Mahmood N, Ringheim K. Factors affecting contraceptive use in Pakistan. Pakistan Development Review. 1996;35(1):1-22.

34. Miah MM. The cultural-structural contexts of high fertility in Bangladesh: A sociological analysis. International Review of Modern Sociology. 1992;22(1):99-110

35. Addai I. Determinants of use of maternal-child health services in rural Ghana. Journal of Biosocial Science. 2000;32(1):1-15.

36. Gyimah SO, Takyi BK, Addai I. Challenges to the reproductive-health needs of African women: On religion and maternal health utilization in Ghana. Socia Science and Medicine. 2006:62(12):2930-44.

37. UNAIDS. AIDS Education through Imams: A spiritually motivated effort in Uganda. 1998. UNAIDS Case Study, UNAIDS/98.33. Available: http://data. unaids.org/ Publications/IRC-pub01/jc126-imams_en.pdf.

38. Raj A, Saggurti N, Balaiah D, Silverman JG. Prevalence of Child Marriage and its Impact on the Fertility and Fertility Control Behaviors of Young Women in India. Lancet 2009:373(9678):1883-9. doi:10.1016/S0140-6736(09)60246-4.

39. Annual Health Survey second Updation Bulletin. 2012-13. available at http:// www.censusindia.gov.in/vital_statistics/AHSBulletins/AHS_Bulletin_2012-13 Presentation.pdf.

40. National Family Health Survey-3, Uttar Pradesh, (2005-2006) Fact Sheet UP. IIPS- Mumbai. 